\title{
Nonnormal Frontal Dynamics
}

\section{Citation}

Feliks, Yizhak, Eli Tziperman, and Brian F. Farrell. 2010. "Nonnormal Frontal Dynamics."

Journal of the Atmospheric Sciences 67 (4) (April): 1218-1231. doi:10.1175/2009jas3214.1. http:// dx.doi.org/10.1175/2009JAS3214.1.

\section{Published Version}

doi:10.1175/2009jas3214.1

\section{Permanent link}

http://nrs.harvard.edu/urn-3:HUL.InstRepos:11892263

\section{Terms of Use}

This article was downloaded from Harvard University's DASH repository, and is made available under the terms and conditions applicable to Other Posted Material, as set forth at http:// nrs.harvard.edu/urn-3:HUL.InstRepos:dash.current.terms-of-use\#LAA

\section{Share Your Story}

The Harvard community has made this article openly available.

Please share how this access benefits you. Submit a story.

Accessibility 


\title{
Nonnormal Frontal Dynamics
}

\author{
YIZHAK FELIKS \\ Department of Mathematics, Israel Institute for Biological Research, Ness-Ziona, Israel \\ ELI TZIPERMAN AND BRIAN FARRELL \\ Department of Earth and Planetary Sciences, and School of Engineering and Applied Sciences, \\ Harvard University, Cambridge, Massachusetts
}

(Manuscript received 3 June 2009, in final form 14 October 2009)

\begin{abstract}
The generalized stability of the secondary atmospheric circulation over strong SST fronts is studied using a hydrostatic, Boussinesq, two-dimensional $f$-plane model. It is shown that even in a parameter regime in which these circulations are stable to small perturbations, significant nonnormal growth of optimal initial perturbations occurs. The maximum growth factor in perturbation total energy is 250 and is dominated by the potential energy, which obtains a growth factor of 219 two to five hours after the beginning of the integration. This domination of potential energy growth is consistent with the observation that the available potential energy (APE) of the secondary circulation is larger by two orders of magnitude than the kinetic energy as well as with the transfer of kinetic to potential perturbation energy at the beginning of the growth of the perturbations.

The norm kernel is found to significantly influence the structure of the optimal initial perturbation as well as the energy obtained by the mature perturbations, but the physical mechanism of growth and the structure of the mature perturbations are robust.
\end{abstract}

\section{Introduction}

Strong SST fronts are found in several parts of the oceans, usually in association with intense oceanic currents such as the Gulf Stream in the Atlantic, the Kuroshio in the Pacific, and the Agulhas Current in the Indian Ocean (O'Neill et al. 2005). Strong SST fronts are also found in the upwelling regions off the western coast of California and in warm and cold core rings (Park et al. 2006). The evolution of the atmospheric marine boundary layer (AMBL) in these regions has been studied observationally and to some extent using analytical and numerical models. Observational evidence shows that the SST front induces a secondary circulation in the AMBL (see reviews by O'Neill et al. 2003; Small et al. 2008), resembling the sea breeze (Hsu 1984): the cool air over the cold water is denser than the warm air over the warm water, resulting in flow at the lower level of the boundary

Corresponding author address: Yizhak Feliks, Dept. of Mathematics, Israel Institute for Biological Research, P.O. Box 19, Ness-Ziona, 70450 Israel.

E-mail: feliks@iibr.gov.il layer of cold air from the cool side of the SST front toward the warm side, while aloft an opposite return flow is found. In cases with the synoptic wind blowing from the cold to warm side of the SST front, the secondary circulation is increased in the lower layer and decreased in the upper layer, and vice versa when the synoptic winds are in the opposite direction. The secondary flow in the lower level diverges and descends over the cold side of the SST front and converges and ascends over the warm side. The atmospheric stratification at a height of $50-130 \mathrm{~m}$ over the warm water is unstable due to the secondary flow that advects cold air over the warm water (Sweet et al. 1981; Small et al. 2008). The height of the AMBL over the warm side of the SST front is greater by several hundreds meters than the height over the cold water.

The surface wind over the warm water is also about twice as strong as that over the cold water. This difference in the surface wind speed results in the observed calmer surface on the cold water side. In the Gulf Stream there is a visible sharp boundary between the two surfaces (see Sweet et al. 1981, their Figs. 1 and 2; Chelton et al. 2006, their Fig. 5). This is also seen in spaceborne 
synthetic aperture radar images (Weissman et al. 1980; Sikora et al. 1995, their Fig. 1). Similar surface roughness boundaries can be observed in other regions where strong SST fronts are found, including the cold and warm core rings of the Gulf Stream (Park et al. 2006) and the Brazil-Malvinas confluence (Tokinaga et al. 2005; O'Neill et al. 2003). In all of these studies the secondary circulation exists under weak to moderate synoptic wind conditions.

The stronger surface wind seen over the warm side of the SST front is conventionally explained by two different mechanisms. One is based on the unstable stratification found in the AMBL. This stratification allows increased vertical turbulence that transports momentum from the prevailing synoptic wind to the sea surface. Small et al. (2008) suggest that the turbulent fluctuations of heat, moisture, and momentum observed over the warm side of the front may be transported deeper into the boundary layer by large eddies to increase the surface wind. An additional mechanism is suggested in which the secondary circulation accelerates the surface winds across the front, producing the stronger wind over the warm part. A summary of the debate of the relative contribution of these two mechanisms to the surface wind can be found in Small et al. (2008). Unfortunately, observational studies of the secondary circulation do not specifically discuss the variability about the mean secondary circulation, which is particularly relevant to the goals of this paper. These studies typically filter the observations to eliminate rapid variability faster than about five days.

Over the warm side of SST fronts the low-level cloud cover is greater, consistent with the ascent there, as observed over the Gulf Stream and over the Agulhas Return Current (Small et al. 2008; Minobe et al. 2008; Sublette and Young 1996, their Fig. 2).

Modeling studies of the dynamics of the mean secondary circulation show features similar to the observed circulation including an increase in the height of the AMBL across the front, the wind over the warm side of the front being significantly stronger than over the cold side, and the flow ascending over the warm SST and descending over the cold SST (Warner et al. 1990; Giordani and Planton 2000; Doyle and Warner 1990; Wai and Stage 1989; Huang and Raman 1988).

The purpose of this paper is to study the dynamics of the variability of the secondary circulation. We use a model of perturbations to a frontal circulation homogeneous in the along-front direction to examine the nonnormal growth of perturbations to a steady secondary circulation in the AMBL induced by a SST front. We show that these perturbations can explain the above observations near SST fronts, including the wind speed, roughness of the sea surface, and cloud bands.

The initial conditions leading to transient growth are referred to as optimal initial conditions (Farrell and Ioannou 1996) and are obtained by solving an eigenvalue problem based on the linearized model equations. The role of transient growth has been studied in the context of atmospheric cyclogenesis (Farrell 1988, 1989), atmospheric predictability (Buizza 1995; Buizza and Palmer 1995), the wind-driven oceanic circulation (Moore 1999), the El Niño-Southern Oscillation variability (Moore and Kleeman 1997; Penland and Sardeshmukh 1995), and the thermohaline circulation (e.g., Lohmann and Schneider 1999; Tziperman and Ioannou 2002).

This paper does not address the synoptic frontogenesis and cyclogenesis problems. These problems have been thoroughly studied, beginning with the studies of Hoskins and Bretherton (1972) and Hoskins (1975). Furthermore, nonnormal growth of large-scale waves on these fronts was studied by Joly (1995).

In the following sections we describe the model equations (section 2), analyze the nonnormal dynamics (section 3 ), and conclude (section 4).

\section{Model equations}

To simplify the analysis, we study a front in the $(x, z)$ plane, where $x$ is the cross-frontal direction and $z$ the vertical direction, assumed homogeneous in the alongfront direction. The perturbations are also assumed homogeneous in the along-front direction. This simplification can be justified because the cross-frontal length scale is about $100 \mathrm{~km}$, while the scale in the along-front dimension is larger by an order of magnitude. The hydrostatic, Boussinesq, $f$-plane model equations are

$$
\begin{aligned}
\frac{\partial u}{\partial t}+u \frac{\partial u}{\partial x}+w \frac{\partial u}{\partial z}-f v & =-\frac{1}{\rho_{m}} \frac{\partial p}{\partial x}+K_{h} \frac{\partial^{2} u}{\partial x^{2}}+K_{v} \frac{\partial^{2} u}{\partial z^{2}} ; \\
\frac{\partial v}{\partial t}+u \frac{\partial v}{\partial x}+w \frac{\partial v}{\partial z}+f u & =K_{h} \frac{\partial^{2} v}{\partial x^{2}}+K_{v} \frac{\partial^{2} v}{\partial z^{2}} \\
\frac{\partial u}{\partial x}+\frac{\partial w}{\partial z} & =0 ; \\
\frac{1}{\rho_{m}} \frac{\partial p}{\partial z} & =-\frac{g \rho}{\rho_{m}} ; \\
\frac{\theta}{\theta_{m}} & =-\frac{\rho}{\rho_{m}} \\
\frac{\partial \theta}{\partial t}+u \frac{\partial \theta}{\partial x}+w \frac{\partial \theta}{\partial z} & =K_{h} \frac{\partial^{2} \theta}{\partial x^{2}}+K_{v} \frac{\partial^{2} \theta}{\partial z^{2}} .
\end{aligned}
$$


The wind components $u, v$, and $w$ are prescribed to vanish at the sea surface. At the upper boundary, $u$ and $v$ are taken to be equal to a specified geostrophic wind $u_{g}$ and $v_{g}$. The upper boundary, at $5440 \mathrm{~m}$, is assumed to be a rigid lid, with $w=0$ there. At the upper boundary $\theta$ is held constant at $318.38 \mathrm{~K}$ and $p$ is determined from the prescribed geostrophic wind. The prescribed sea surface temperature difference across the front is $5^{\circ} \mathrm{C}$ and the front width is $100 \mathrm{~km}$. Away from the front region the SST gradient vanishes. The geostrophic circulation is assumed to be determined by larger-scale processes not represented here. On the short time scales of interest in this paper, the geostrophic circulation is unaffected by the SST gradients, which have a small spatial scale compared to a typical tropospheric Rossby radius of deformation (Feliks et al. 2004, 2007).

At the horizontal boundaries the normal derivatives of $u, v$, and $\theta$ are set to zero. Convective adjustment is applied during the model integration when the modeled lapse rate is $10^{-2} \mathrm{~K} \mathrm{~km}^{-1}$, slightly larger than the neutral lapse rate. Numerical details and physical parameters are summarized in the appendix. Note that these equations include the Ekman dynamics expected to be critical within the AMBL.

We run the nonlinear model forced by the SST front until the secondary circulation reaches a steady state. We linearized the model given in (1) about this steady secondary circulation. Then we let $\rho=\rho_{m}+\rho^{\prime}$, where $\rho^{\prime}$ is the perturbation density, and similarly introduce small perturbations to the other fields $u^{\prime}, v^{\prime}, \theta^{\prime}$, etc. The boundary conditions for the perturbations are such that $u^{\prime}, v^{\prime}, w^{\prime}$, and $\theta^{\prime}$ vanish at the upper and lower boundaries. At the horizontal boundaries, the normal derivative of $u^{\prime}, v^{\prime}$, and $\theta^{\prime}$ is set to zero, as in the fully nonlinear model.

The computational domain over which the nonlinear model was integrated to find the base steady state is $500 \mathrm{~km}$ wide in the $x$ direction and extends from the surface to a height of $5440 \mathrm{~m}$. The integration domain for the linearized model used to analyze the nonnormal dynamics extends over the part of the computational domain of the full nonlinear model extending between 100 and $450 \mathrm{~km}$ along the $x$ axis and 0 to $3200 \mathrm{~m}$ along the $z$ axis. While the domain does not include the entire free troposphere, we ran the nonlinear model with a height of $8000 \mathrm{~m}$ instead of $5440 \mathrm{~m}$ and the mean circulation was practically identical. We also repeated the linear analysis of the first experiment with a height of $2880 \mathrm{~m}$ instead of $3200 \mathrm{~m}$, and the results did not change, indicating that the results are not sensitive to the vertical extent of the model. Note that the plotted domain in the figures below is often smaller than the full model domain, as we often plot only parts of the domain where interesting signals develop. See the appendix for more details.

Integrating the kinetic energy equation over the domain and utilizing the boundary conditions we find

$$
\begin{aligned}
\frac{\partial\left\langle E_{k}\right\rangle}{\partial t}= & \frac{1}{2} \frac{\partial}{\partial t}\left(\left\langle u^{\prime 2}\right\rangle+\left\langle v^{\prime 2}\right\rangle\right)=-\left\langle u^{\prime 2} \bar{u}_{x}\right\rangle-\left\langle u^{\prime} w^{\prime} \bar{u}_{z}\right\rangle+\left\langle w^{\prime} \theta^{\prime} \frac{g}{\theta_{m}}\right\rangle-\left\langle v^{\prime} u^{\prime} \bar{v}_{x}\right\rangle-\left\langle v^{\prime} w^{\prime} \bar{v}_{z}\right\rangle-K_{h}\left(\left\langle\left(u_{x}^{\prime}\right)^{2}\right\rangle+\left\langle\left(v_{x}^{\prime}\right)^{2}\right\rangle\right) \\
& -K_{v}\left(\left\langle\left(u_{z}^{\prime}\right)^{2}\right\rangle+\left\langle\left(v_{z}^{\prime}\right)^{2}\right\rangle\right)+\left\{\left[\frac{1}{\rho_{m}} u^{\prime} p^{\prime}+\bar{u} u^{\prime 2}+\bar{u} v^{\prime 2}\right]\right\}_{x_{w}}^{x_{e}}
\end{aligned}
$$

in which angle brackets denote the integral over the domain, square brackets the vertical integral with respect to $z$, and braces the difference of the enclosed term between the horizontal boundaries (i.e., the net flux into the domain through the vertical side boundaries).

The integrated available potential energy equation is obtained by multiplying the $\theta^{\prime}$ equation by $\alpha \theta^{\prime}$ with

$$
\alpha=g\left(\theta_{m} \frac{\partial \bar{\theta}}{\partial z}\right)^{-1}
$$

integrating over the domain, and using the boundary conditions

$$
\begin{aligned}
\frac{\partial\left\langle E_{p}\right\rangle}{\partial t}= & \frac{1}{2} \frac{\partial}{\partial t}\left\langle\alpha \theta^{\prime 2}\right\rangle=-\left\langle\alpha \theta^{\prime} u^{\prime} \frac{\partial \bar{\theta}}{\partial x}\right\rangle-\left\langle w^{\prime} \theta^{\prime} \frac{g}{\theta_{m}}\right\rangle+\left\langle\frac{\theta^{\prime 2}}{2} \bar{u} \frac{\partial \alpha}{\partial x}\right\rangle+\left\langle\frac{\theta^{\prime 2}}{2} \bar{w} \frac{\partial \alpha}{\partial z}\right\rangle-K_{h}\left\langle\alpha\left(\theta_{x}^{\prime}\right)^{2}\right\rangle \\
& -K_{v}\left\langle\alpha\left(\theta_{z}^{\prime}\right)^{2}\right\rangle+\left\{\left[\bar{u} \alpha \theta^{\prime 2}\right]\right\}_{x_{w}}^{x_{e}} .
\end{aligned}
$$



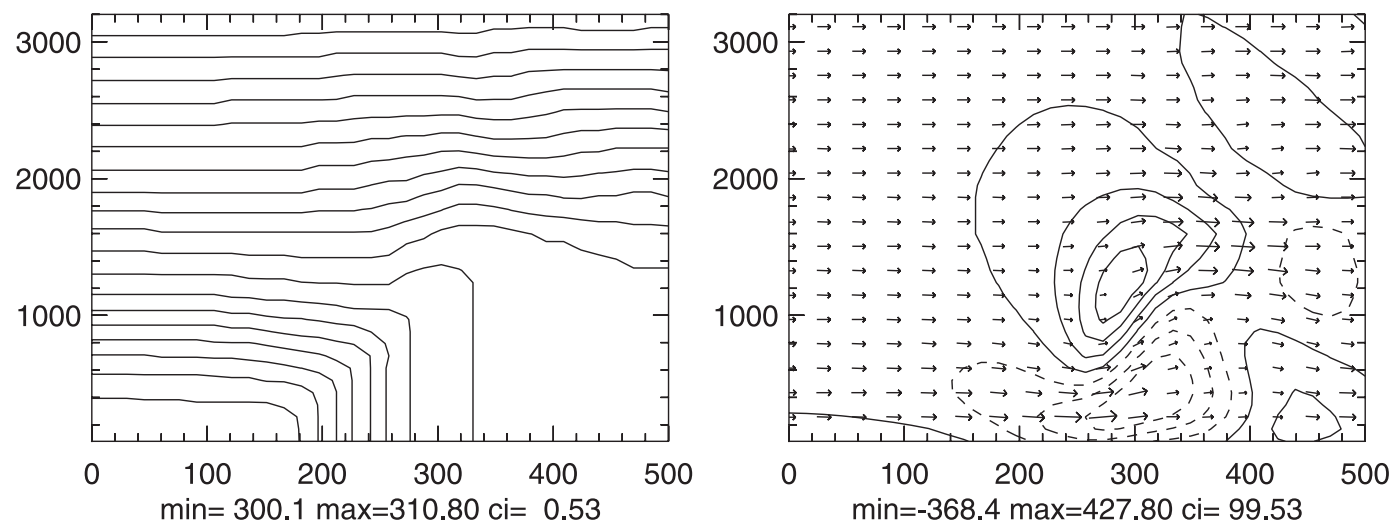

FIG. 1. Vertical cross-front section $[x(\mathrm{~km}), z(\mathrm{~m})]$ of the steady secondary circulation as obtained by the nonlinear model for $u_{g}=3 \mathrm{~m} \mathrm{~s}^{-1}, v_{g}=0$. The warm water is to the right of the front. (left) Potential temperature $\bar{\theta}$ with contours in $\mathrm{K}$; (right) Wind field vectors for $\bar{u}$ and $\bar{w}$. The maximum in the cross-frontal circulation is $\max (\bar{u})=6.7 \mathrm{~m} \mathrm{~s}^{-1}$ and for the vertical wind $\max (\bar{w})=3.7 \mathrm{~cm} \mathrm{~s}^{-1}$. Contours are of the along-front wind $\bar{v}\left(\mathrm{~cm} \mathrm{~s}^{-1}\right)$. Note that the vertical extent of the plotted domain is smaller than the actual computational domain (see section 2 and the appendix).

The integrated total energy equation is therefore

$$
\begin{aligned}
\frac{\partial\left\langle E_{T}\right\rangle}{\partial t}= & \frac{1}{2} \frac{\partial}{\partial t}\left(\left\langle u^{\prime 2}\right\rangle+\left\langle v^{\prime 2}\right\rangle+\left\langle\alpha \theta^{\prime 2}\right\rangle\right)=-\left\langle u^{\prime 2} \frac{\partial \bar{u}}{\partial x}\right\rangle-\left\langle u^{\prime} w^{\prime} \frac{\partial \bar{u}}{\partial z}\right\rangle-\left\langle v^{\prime} u^{\prime} \frac{\partial \bar{v}}{\partial x}\right\rangle-\left\langle v^{\prime} w^{\prime} \frac{\partial \bar{v}}{\partial z}\right\rangle-\left\langle\alpha \theta^{\prime} u^{\prime} \frac{\partial \bar{\theta}}{\partial x}\right\rangle \\
& +\left\langle\frac{\theta^{\prime 2}}{2} \bar{u} \frac{\partial \alpha}{\partial x}\right\rangle+\left\langle\frac{\theta^{\prime 2}}{2} \bar{w} \frac{\partial \alpha}{\partial z}\right\rangle-K_{h}\left(\left\langle\left(u_{x}^{\prime}\right)^{2}\right\rangle+\left\langle\left(v_{x}^{\prime}\right)^{2}\right\rangle+\left\langle\alpha\left(\theta_{x}^{\prime}\right)^{2}\right\rangle\right)-K_{v}\left(\left\langle\left(u_{z}^{\prime}\right)^{2}\right\rangle+\left\langle\left(v_{z}^{\prime}\right)^{2}\right\rangle+\left\langle\alpha\left(\theta_{z}^{\prime}\right)^{2}\right\rangle\right) \\
& +\left\{\left[\frac{1}{\rho_{m}} u^{\prime} p^{\prime}+\bar{u} u^{\prime 2}+\bar{u} v^{\prime}+\bar{u} \alpha \theta^{\prime 2}\right]\right\}_{x_{w}}^{x_{e}} .
\end{aligned}
$$

\section{Calculating the optimal initial conditions}

Using finite differencing the linearized equations for $u^{\prime}, v^{\prime}$, and $\theta^{\prime}$ may be written in vector form as

$$
\mathbf{P}_{n+1}=\mathbf{B P}_{n}=\mathbf{B}^{n} \mathbf{P}_{0},
$$

where $\mathbf{P}$ is the state vector of anomalies on the model 2D grid, $\mathbf{P}=\left[u_{1}^{\prime}, u_{2}^{\prime}, \ldots, u_{k}^{\prime}, v_{1}^{\prime}, v_{2}^{\prime}, \ldots, v_{k}^{\prime}, \theta_{1}^{\prime}, \theta_{2}^{\prime}, \ldots, \theta_{k}^{\prime}\right], k$ is the total number of grid points, and $\mathbf{B}$ is the $3 k \times 3 k$ propagator (matrix) of the finite difference linearized model.

Define the energy norm kernel, $\mathbf{X}$, to be a matrix such that $\mathbf{P}(\tau)^{\mathrm{T}} \mathbf{X P}(\tau)$ is the total perturbation energy at a time $\tau$. The optimal initial conditions that maximize the state vector norm $\mathbf{P}(\tau)^{\mathrm{T}} \mathbf{X} \mathbf{P}(\tau)$ at a time $\tau=n d t$, subject to $\mathbf{P}(0)^{\mathrm{T}} \mathbf{Y} \mathbf{P}(0)=1$, where $\mathbf{Y}$ may be a different norm kernel (possibly constraining the amplitude of the optimal initial condition under a different norm), are found by solving the eigenproblem (Farrell 1988, 1989; Farrell and Ioannou 1996)

$$
\mathbf{Y}^{-1} \mathbf{B}^{n \mathrm{~T}} \mathbf{X} \mathbf{B}^{n} \mathbf{e}=\lambda \mathbf{e}
$$

where $\mathbf{e}$ is the eigenvector.

\section{Analysis}

\section{a. Steady circulation}

The steady circulation in the atmosphere in the lower $3200 \mathrm{~m}$ above the SST front, as obtained by integrating the nonlinear model (1), with the geostrophic wind set to $u_{g}=3 \mathrm{~m} \mathrm{~s}^{-1}, v_{g}=0$, is shown in Fig. 1. The depth of the AMBL is $320 \mathrm{~m}$ over the cold side of the SST front and $1500 \mathrm{~m}$ over the warm side. Above the AMBL there is a strong inversion over the cold side of the SST front and a much weaker inversion over the warm side. The secondary circulation is prominent in the AMBL and the layer above it. The structure of the steady circulation obtained in the nonlinear model-including the flow of cold air and return flow, ascending and descending motions, and the along-frontal velocity-is consistent with observations of secondary circulations as described in the introduction. Standing waves originating in the location of maximum speed and tilting toward the warm side of the domain with wavelength $1500 \mathrm{~m}$ in the vertical and $120 \mathrm{~km}$ in the horizontal are evident. 


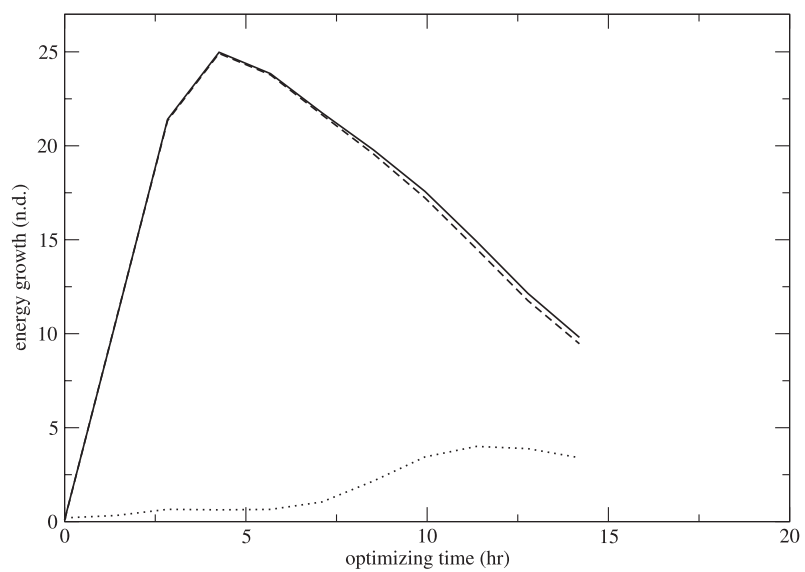

FIG. 2. The maximum perturbation energy growth as a function of optimizing time $\tau$ : the total energy divided by $10,\left\langle E_{T}(\tau)\right\rangle /$ $\left\langle E_{T}(0)\right\rangle / 10$ (solid line); the potential energy divided by $10,\left\langle E_{P}(\tau)\right\rangle /$ $\left\langle E_{T}(0)\right\rangle / 10$ (dashed line); and the kinetic energy, $\left\langle E_{K}(\tau)\right\rangle /\left\langle E_{T}(0)\right\rangle$ (dotted line).

A linear stability analysis of the propagator $\mathbf{B}$ in (5) shows that the absolute value of the largest eigenvalues of $\mathbf{B}$ is smaller than 1 . The propagator is therefore stable to small perturbations, and the growth in the energy of initial perturbations can only arise from the nonnormality of the propagator.

\section{b. Nonnormal growth}

The norm kernels $\mathbf{X}$ and $\mathbf{Y}$ in (6) that we used in the experiments of this section are both set to the total energy norm $E_{T}$ based on (4). We calculate the initial conditions that lead to the maximal total energy at $t=\tau$, and the growth factors for the total, kinetic, and potential energies that result at time $t$ are defined as $\left\langle E_{T, k, p}(t)\right\rangle /$ $\left\langle E_{T}(0)\right\rangle$. The potential energy calculation takes into account the spatial changes of the mean stratification via the variations of $\alpha(x, z)$. The growth factors at the optimization time $\tau$ are shown in Fig. 2 for $\left\langle E_{T}\right\rangle,\left\langle E_{p}\right\rangle$, and $\left\langle E_{k}\right\rangle$ as a function of $\tau ;\left\langle E_{T}\right\rangle$ and $\left\langle E_{p}\right\rangle$ reach their maximum at $\tau=4.2 \mathrm{~h}$ : the total energy growth factor is 249 and is nearly all due to potential energy growth. The kinetic energy reaches its maximum growth at $\tau=12.1 \mathrm{~h}$, and the corresponding growth factor is 4.7. This large difference in the time of the maximum growth of the potential and kinetic energies is an indication of different dynamics in different stages of the evolution, as will be shown below.

To analyze the growth mechanism we examine in detail the evolution of the initial perturbation for an optimizing time of $\tau=12.1 \mathrm{~h}$, the optimizing time for which $\left\langle E_{k}\right\rangle$ reaches its maximum growth. The energy growth as function of time is shown in Fig. $3 ;\left\langle E_{T}\right\rangle$ and $\left\langle E_{p}\right\rangle$ reach their maximum growth at $t=6.4 \mathrm{~h}$. The

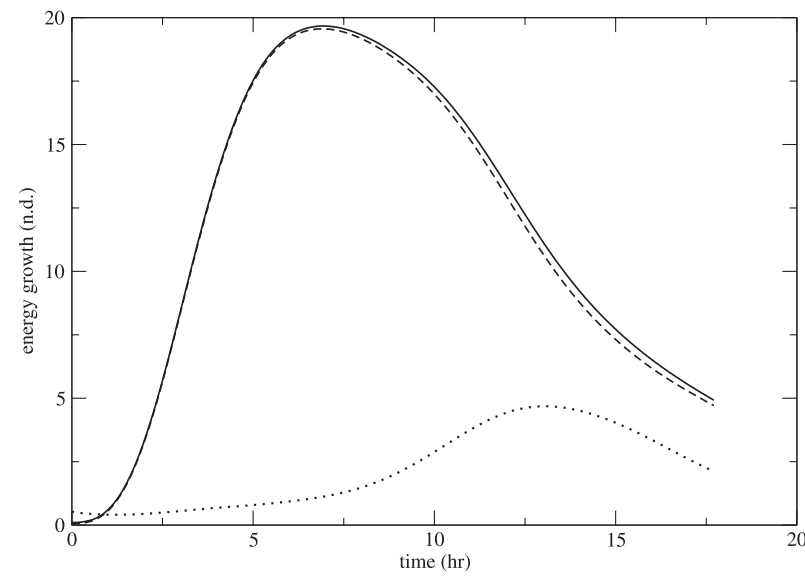

FIG. 3. The energy growth of optimal initial perturbation at $\tau=$ $12.1 \mathrm{~h}$ as a function of time: $\left\langle E_{T}(\tau)\right\rangle /\left\langle E_{T}(0)\right\rangle / 10$ (solid line); the potential energy, $\left\langle E_{P}(\tau)\right\rangle /\left\langle E_{T}(0)\right\rangle / 10$ (dashed line); and the kinetic energy, $\left\langle E_{K}(\tau)\right\rangle /\left\langle E_{T}(0)\right\rangle$ (dotted line).

maximum growth factor is 196 , somewhat smaller than the maximum growth (Fig. 2) that occurs for $\tau=4.2 \mathrm{~h}$. In Figs. 4-6 the initial optimal perturbation and its evolved state at $t=6.4$ and $12.1 \mathrm{~h}$ are shown. The initial perturbation is found to be concentrated over the cold side of the domain, mainly in the frontal region just above the AMBL.

At later times the perturbation propagates toward the warm side owing to advection by the mean flow. In the first $6.4 \mathrm{~h}$ the perturbation reaches the warm edge of the front and evolves into a well-organized $u^{\prime}, w^{\prime}$ cell (Fig. 5) in the AMBL with significant signals of potential temperature and along-front velocity. The horizontal scale of the cell is about $50 \mathrm{~km}$. At later times the evolution changes significantly, and the propagation speed of the perturbation toward the warm side decreases by a factor of 2 (Fig. $6, t=12.1 \mathrm{~h}$ ) due to the large decrease in the mean horizontal velocity at the warm edge of the front (Fig. 1). The strengths of $u^{\prime}$ and $w^{\prime}$ in the cell, as well as of $v^{\prime}$, increase significantly and an additional strong cell with an opposite circulation develops in the cold side of the main cell. The perturbations also expand to the upper layers above the AMBL. Between the two cells a very strong updraft is observed. This strong updraft would give rise to low-level clouds as observed in the Gulf Stream over the warm side of the front (Small et al. 2008; Minobe et al. 2008; Sublette and Young 1996). The $\theta^{\prime}$ perturbations are advected into the upper layers and reach the top of the domain. At later times the perturbations continue to propagate slowly toward the warm side of the front. At this time the amplitude of the perturbations begins to decrease, as can be seen in Fig. 3 for $E_{k}$. At later times $(t=17 \mathrm{~h})$ the perturbations moves out of the domain through the warm part of the front. 
(a) time $=0.0$

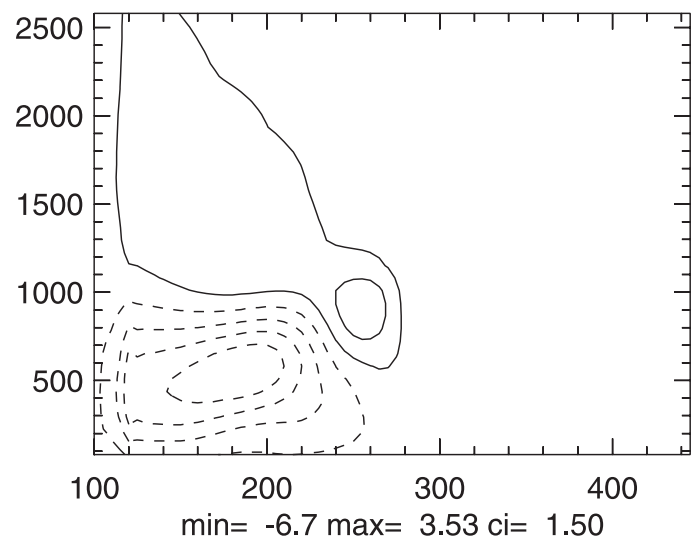

(c) time $=0.0$

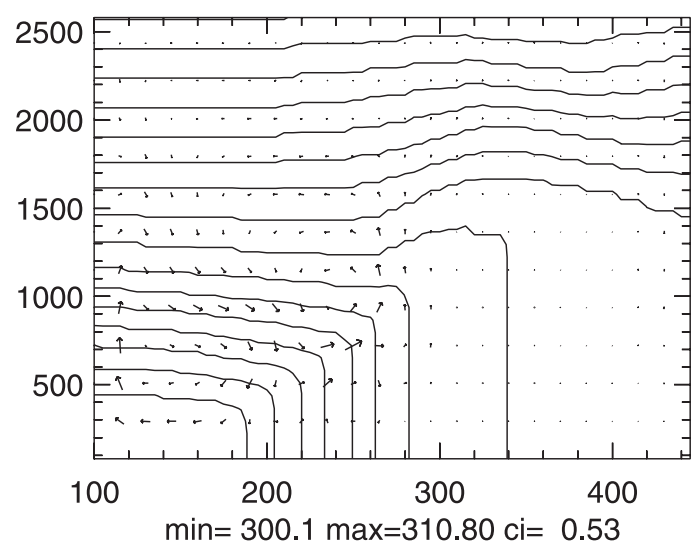

As is typical for nonnormal growth, the energy tendency

$$
\frac{1}{E_{T}(t)} \frac{\partial E_{T}(t)}{\partial t}=\frac{1}{E_{T}(t)} \frac{\partial E_{P}(t)}{\partial t}+\frac{1}{E_{T}(t)} \frac{\partial E_{K}(t)}{\partial t}
$$

changes with time, as shown for our case in Fig. 7. In normal (exponential) growth the energy tendency and the tendency terms are constant. The energy tendency has an upper bound that is a function of the mean field only. This upper limit is the value of the energy tendency in the limit $\tau \rightarrow 0$. In our case the growth rate in this limit is $0.0025 \mathrm{~s}^{-1}$, that is, four times larger than the maximum energy tendency obtained in our case with $\tau=12.1 \mathrm{~h}$.

To understand the growth mechanism, we examine the role of the different tendency terms in the energy equations (2), (3), and (4) divided by $\left\langle E_{T}\right\rangle$ (these terms are indicated by an asterisk). The main points are briefly summarized in the following subsection.

In the equation for $\left\langle E_{p}\right\rangle^{*}$ the dominant term during the first $10 \mathrm{~min}$ is the conversion of kinetic energy to potential energy, $-\left\langle w^{\prime} \theta^{\prime} g / \theta_{0}\right\rangle^{*}=1.4 \times 10^{-5} \mathrm{~s}^{-1}$. Later, the significant terms are $\left\langle\alpha u^{\prime} \theta^{\prime} \bar{\theta}_{x}\right\rangle^{*}$, which we refer to later as "the horizontal buoyancy flux," $1 / 2\left\langle\theta^{\prime 2} \bar{u} \alpha_{x}\right\rangle^{*}$, (b) time $=0.0$

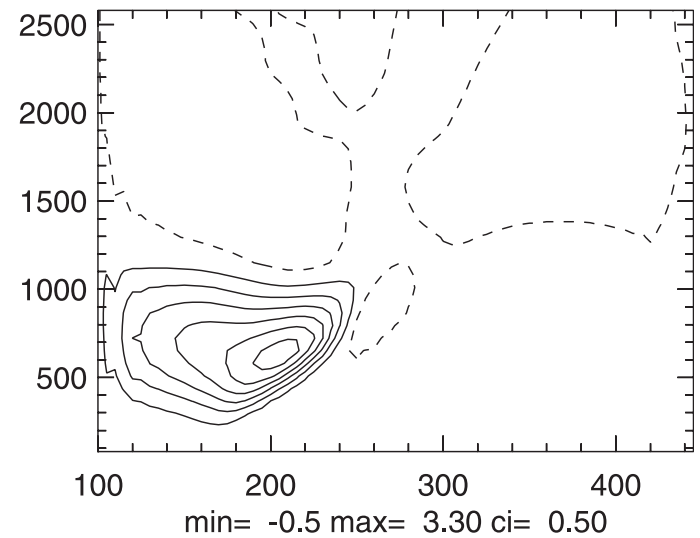

FIG. 4. Optimal initial perturbation of expt 1 at optimizing time $\tau=12.1 \mathrm{~h}$ over the front (showing only the part of the domain over the front): (a) $v$ velocity $\left(\mathrm{cm} \mathrm{s}^{-1}\right.$, contour interval $\left.=1.5\right)$; (b) potential temperature (units are $=0.01 \mathrm{~K}$ ); (c) mean potential temperature contours (units are $1 \mathrm{~K}$ ) superimposed on wind field vectors for the optimal perturbation of $u^{\prime}, w^{\prime}$ : $\max \left(u^{\prime}\right)=5 \mathrm{~cm} \mathrm{~s}^{-1} ; \max \left(w^{\prime}\right)=0.06 \mathrm{~cm} \mathrm{~s}^{-1}$.

$1 / 2\left\langle\theta^{\prime 2} \bar{w} \alpha_{z}\right\rangle^{*}$, and $-K_{v}\left\langle\alpha\left(\theta_{z}^{\prime}\right)^{2}\right\rangle^{*}$. These terms are larger by at least one order of magnitude than the other terms between $t=0$ and $15 \mathrm{~h}$, shown in Fig. 8. The initial positive perturbation $\theta^{\prime}$ (Fig. 4) is elongated along the line where $\alpha$ has the largest horizontal gradient. As this $\theta^{\prime}$ perturbation is advected toward the warm side of the front and downward by the mean horizontal and vertical flow $\bar{u}, \bar{w}$, it gains available potential energy. As the perturbations reach the warm side of the front, the horizontal gradients of $\bar{\theta}$ and $\alpha$ decrease, so do the above perturbation energy source terms. This, together with the vertical diffusion, leads to the decrease of $\left\langle E_{p}\right\rangle$ (Fig. 3).

In the evolution of kinetic energy we notice several stages. During the first half hour, the largest term is the buoyancy generation by $\left\langle w^{\prime} \theta^{\prime} g / \theta_{0}\right\rangle^{*}=-1.4 \times 10^{-5} \mathrm{~s}^{-1}$, resulting in the transfer of kinetic to potential energy. At later times this term reverses, increasing the kinetic energy.

The Reynolds stress terms

$$
-\left\langle u^{\prime} w^{\prime} \frac{\partial \bar{u}}{\partial z}\right\rangle^{*},-\left\langle v^{\prime} w^{\prime} \frac{\partial \bar{v}}{\partial z}\right\rangle^{*},-\left\langle v^{\prime} u^{\prime} \frac{\partial \bar{v}}{\partial x}\right\rangle^{*}
$$


(a) time $=6.4$

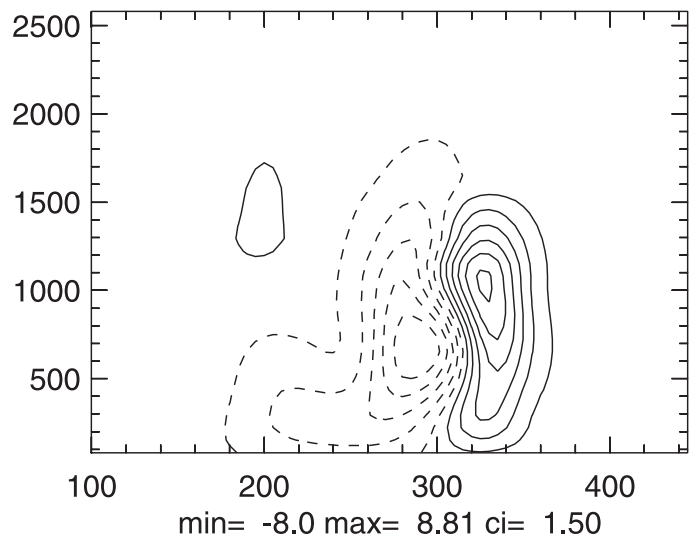

(c) time $=6.4$

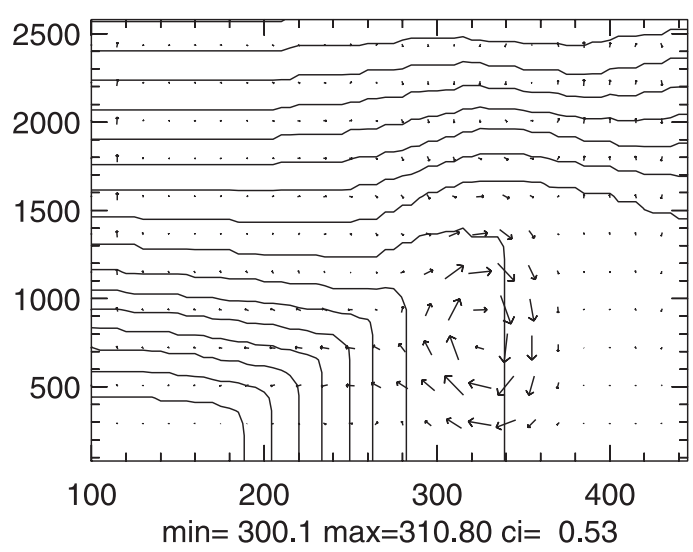

are positive during most of the evolution, resulting in increasing perturbation kinetic energy via energy extracted from the mean flow.

However, this is not the case at all times and locations. For example, perturbation energy growth occurs due to perturbation interaction with the front during the first $6 \mathrm{~h}$, or so, until the perturbation reaches the warm edge of the front. After this point, we find that momentum (and energy) is transferred from the perturbation to the mean flow, which tends to increase the mean surface flow (Figs. 1 and 5), with observational consequences to be discussed below. In addition, interaction between perturbations and the mean flow produces effects in the free troposphere above the boundary layer, up to about $2 \mathrm{~km}$, that play an important part in the growth process.

\section{c. Summary of growth mechanism}

From the above analysis we conclude that the evolution of the perturbations may be divided into four main stages. The first stage is very short, lasting less than half an hour, and during this stage the kinetic energy is converted to potential energy. In the second stage, $1 / 2<t<7 \mathrm{~h}$, the (b) time $=6.4$

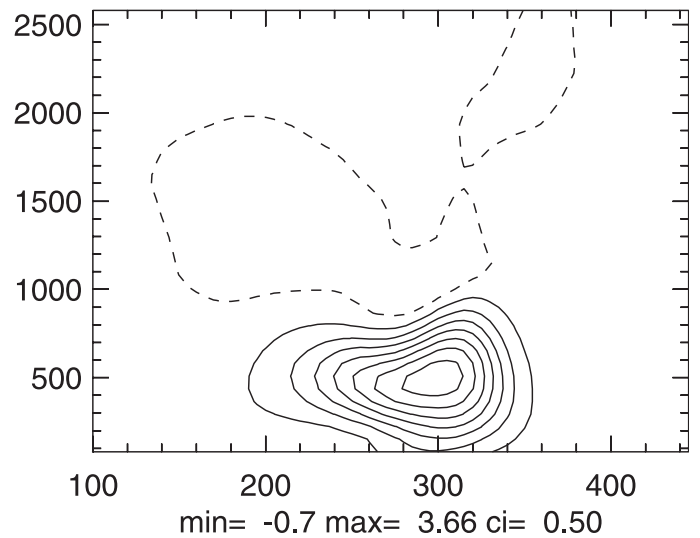

FIG. 5. Optimal perturbation of expt 1 at $t=6.4 \mathrm{~h}$, panels and contour levels as in Fig. 4: $\max \left(u^{\prime}\right)=$ $7.7 \mathrm{~cm} \mathrm{~s}^{-1} ; \max \left(w^{\prime}\right)=0.12 \mathrm{~cm} \mathrm{~s}^{-1}$.

available potential energy increases rapidly owing to energy transfer from the mean thermal front via advection by $u^{\prime}$ and movement of the perturbations toward a region with lower stability. The kinetic energy increases due to conversion from potential energy and extraction from the mean shear, and there is momentum transfer between $u^{\prime}$ and $v^{\prime}$ by the Coriolis force.

As the perturbations are advected to the warm side of the front, the third stage of the evolution begins, extending over $7<t<17 \mathrm{~h}$. During this stage the structure of $\theta^{\prime}$ changes dramatically, and the potential energy decreases via upward advection of the perturbations by $\bar{w}$ toward the inversion, over the warm edge of the front. During the fourth stage, $t>17 \mathrm{~h}$, the perturbations are located to the right of the front where the energy source terms are very small, and the kinetic energy now decreases because of the dissipation terms.

The above description of the evolution of the initial optimal perturbation for $\tau=12 \mathrm{~h}$ is very similar to the evolution of any optimal initial perturbations calculated for $2<\tau<13 \mathrm{~h}$. The main differences between the evolution of optimal perturbations calculated for 
(a) time $=12.1$

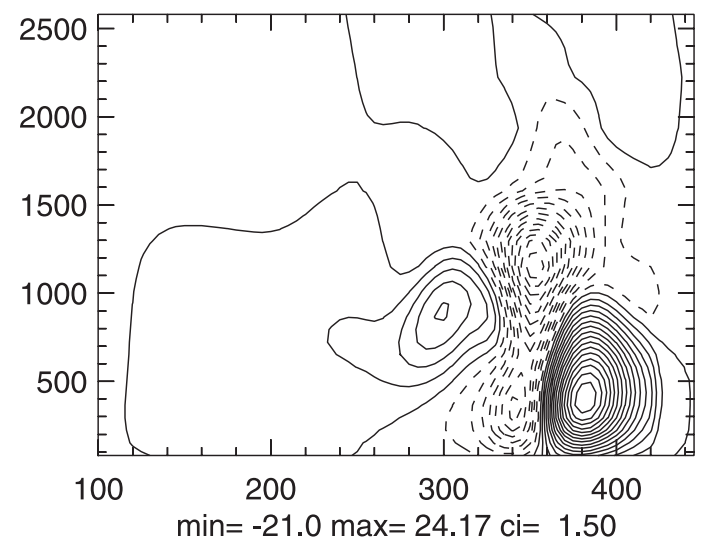

(c) time $=12.1$

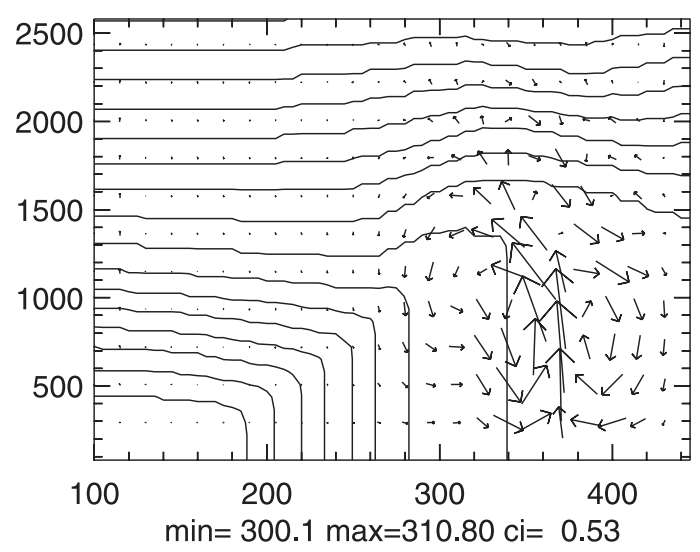

different values of $\tau$ are in the timing of the maximum growth, the time and length of each stage of the evolution, and the amplitude of the perturbations at the different stages.

\section{d. Observable consequences}

In the above analysis we found that the perturbations in $u^{\prime}, v^{\prime}$, and $w^{\prime}$ grow mainly at the warm side of the front. We also showed that these growing eddies result in a momentum transfer from an altitude where the wind is strong (above $300 \mathrm{~m}$ ) down to the surface and can contribute to the increasing of the mean surface wind over the warm side of the SST front. Note that this transfer is independent of the sign of the perturbation. Our analysis has therefore two predictions that may be checked against observations: first, that the wind variability, excited via the nonnormal transient amplification, is expected to be stronger over the warm side of the front and, second, that the mean wind should be stronger over the warm side due to the momentum transfer by the growing perturbations. As mentioned in the introduction, the observations seem to suggest that the mean wind is indeed stronger over this warm side, yet do not (b) time $=12.1$

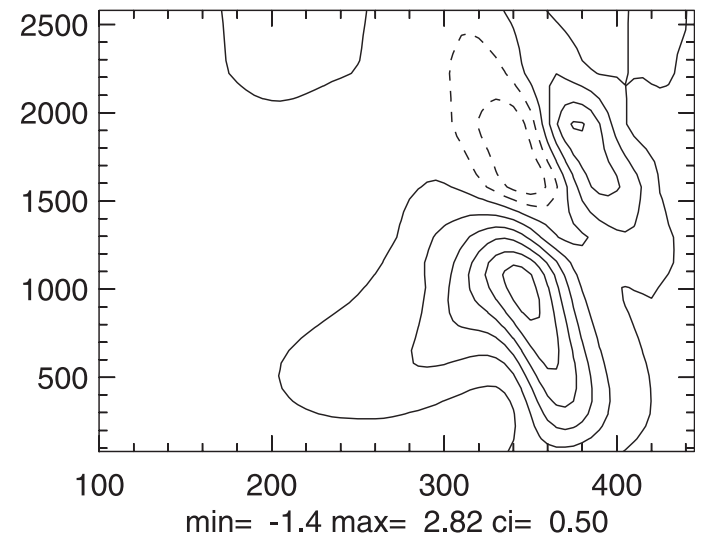

Fig. 6. As in Fig. 5 but at $t=12.1$ h: $\max \left(u^{\prime}\right)=$ $15 \mathrm{~cm} \mathrm{~s}^{-1} ; \max \left(w^{\prime}\right)=0.4 \mathrm{~cm} \mathrm{~s}^{-1}$.

seem to explicitly address the difference in variability (e.g., rms wind variability) between the warm and cold sides of the front. Additionally, we find that the strong updraft that develops from the optimal initial perturbations

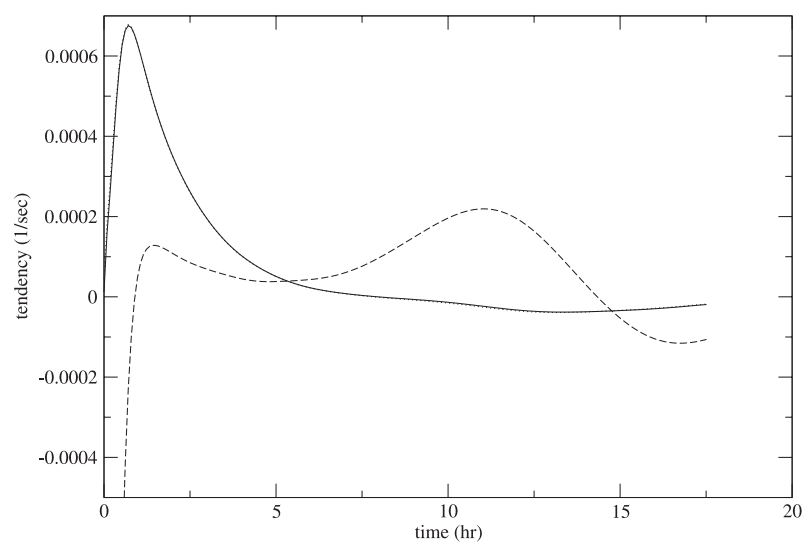

FIG. 7. Energy tendency of the optimal perturbation for optimizing time $\tau=12.1 \mathrm{~h}$ as a function of time: $\left[1 / E_{T}(t)\right]\left[\partial E_{T}(t) / \partial t\right]$ (solid line); the potential energy tendency, $\left[1 / E_{T}(t)\right]\left[\partial E_{P}(t) / \partial t\right]$ (solid line, overlapping the total energy curve); and the kinetic energy tendency multiply by $100,100\left[1 / E_{T}(t)\right]\left[\partial E_{K}(t) / \partial t\right]$ (dashed line). 


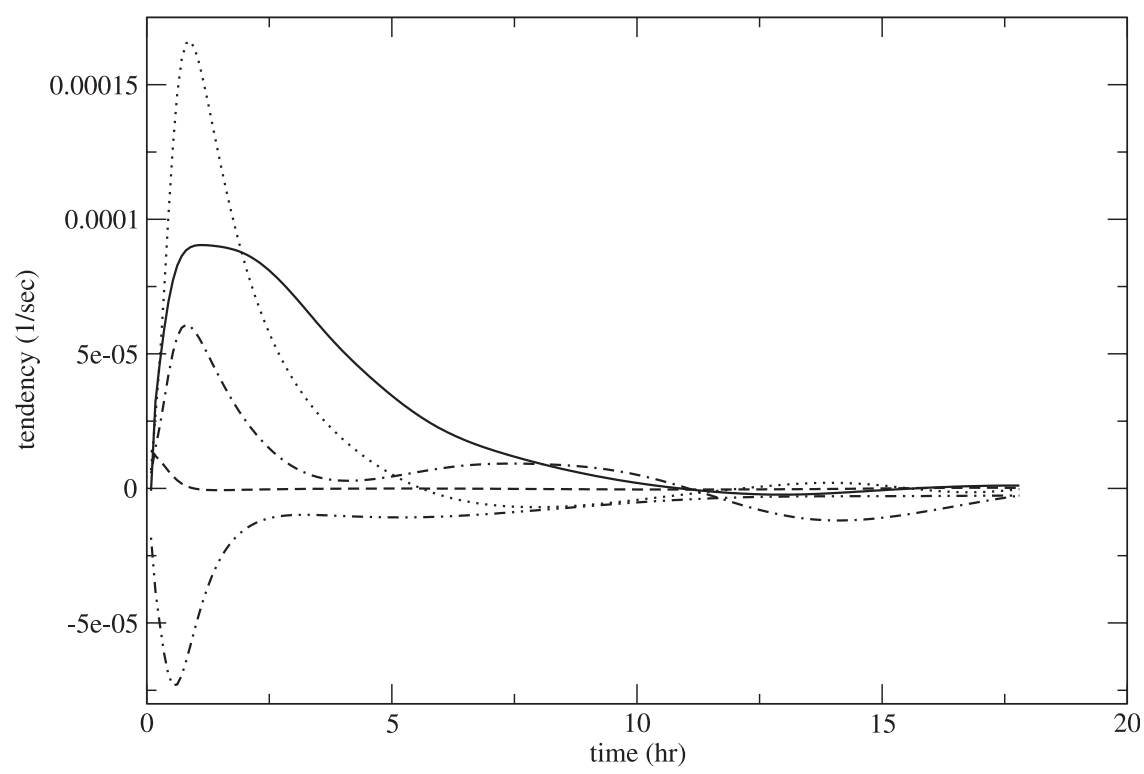

FIG. 8. Tendency terms in the potential energy equation (3) for experiment $1:-\left\langle\theta^{\prime} u^{\prime}(\partial \bar{\theta} / \partial x)\right\rangle$ (solid line), $\left\langle\theta^{\prime 2} \bar{u}(\partial \alpha / \partial x)\right\rangle$ (dotted line), $\left\langle\theta^{\prime 2} \bar{w}(\partial \alpha / \partial z)\right\rangle$ (dash-dot line), $-K_{v}\left\langle\alpha\left(\partial \theta^{\prime} / \partial z\right)^{2}\right\rangle$ (dashdot-dot line), and $-\left\langle w^{\prime} \theta_{g}^{\prime} / \theta_{0}\right\rangle$ (dashed line).

at the warm edge of the front penetrates into the inversion and reaches high altitudes. This can also explain the low-level clouds found in observations over the warm SST side of fronts (e.g., over the Gulf Stream and the Agulhas Return Current) (Small et al. 2008; Sublette and Young 1996; Minobe et al. 2008).

\section{e. Sensitivity to the prescribed large-scale geostrophic velocity}

In this section we examine the influence of the prescribed geostrophic wind on the secondary circulation and the nonnormal growth. We found that, of all the model variables, the two parameters denoting the geostrophic wind components seem to result in the most interesting and perhaps least expected sensitivity behavior: therefore, we concentrate on these parameters. We refrain from showing the sensitivity to other parameters to avoid extending the length of the presentation. In experiment 2 we decrease the geostrophic wind to $u_{g}=1.5$ and $v_{g}=0 \mathrm{~m} \mathrm{~s}^{-1}$. The resulting steady circulation is very similar to that in experiment 1, Fig. 1. The main differences are the larger gradient in $\bar{v}$ and slower $\bar{u}$ in this experiment. The maximum growth factor of the total and potential energy is 205 (as compared with 249 in experiment 1 where $u_{g}=3 \mathrm{~m} \mathrm{~s}^{-1}, v_{g}=0$ ) and is obtained by $\tau=2.8 \mathrm{~h}$. The maximum growth factor of kinetic energy is 20 (compared to 4.7 in experiment 1) and is obtained by $\tau=15.6 \mathrm{~h}$. The optimal initial perturbation is similar to that of experiment 1 (Fig. 4) in $u^{\prime}, w^{\prime}$, and $v^{\prime}$, but less so in $\theta^{\prime}$. The structure of the maximally amplified perturbations is very similar, but the location of the maximum in this case is about $30 \mathrm{~km}$ farther toward the cold part of the front relative to that in experiment 1 . These differences between the two experiments result from the differences between their secondary circulations. The slower $\bar{u}$ results in slower advection of the perturbations toward the warm SST, so the perturbations have more time to extract energy from the mean steady flow so that the maximum growth of the kinetic energy is at $t=15.6 \mathrm{~h}$ (i.e., $3.5 \mathrm{~h}$ later than in experiment 1). The larger gradient in $\bar{v}$ tends to increase the rate of energy transfer from the mean flow. On the other hand, the larger gradient of $\bar{u}$ in experiment 1 tends to increase the transfer rate in experiment 1.

In experiment 3 we set the geostrophic wind to zero: $u_{g}=v_{g}=0$. The steady secondary circulation for this experiment, shown in Fig. 9, is substantially different from the previous cases of experiments 1 (Fig. 1) and 2 (not shown, similar to experiment 1 ). The differences in the wind component parallel to the thermal front, $\bar{v}$, between the steady state of experiment 3 and the previous runs have a large effect on the calculated optimal perturbations. This is seen when comparing the optimal initial conditions for $\tau=2.8 \mathrm{~h}$ in experiment 3 (Fig. 10) with the optimal initial conditions for experiment 1 (Fig. 4, note that this figure is for $\tau=12.1 \mathrm{~h}$, but the results are similar if $\tau=2.8 \mathrm{~h}$ is used). The evolved state from these initial conditions for experiment 3 , at $t=2.8 \mathrm{~h}$, is shown in Fig. 11. Since the perturbation does not move through 

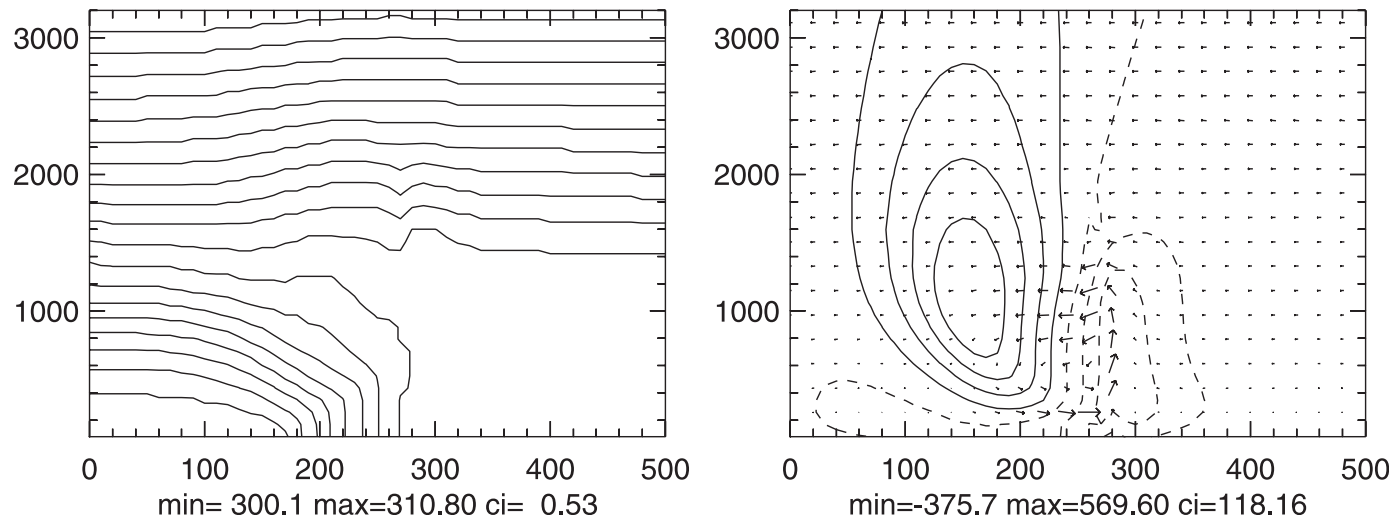

FIG. 9. Vertical cross-front section of the steady secondary circulation as obtained by the nonlinear model in expt 3 for $u_{g}=0 \mathrm{~m} \mathrm{~s}^{-1}$ and $v_{g}=0$, panels and contours as in Fig. $1: \max (\bar{u})=5.4 \mathrm{~m} \mathrm{~s}^{-1} ; \max (\bar{w})=12 \mathrm{~cm} \mathrm{~s}^{-1}$.

the areas with largest shear, it does not extracts kinetic energy from $\bar{v}$, so the kinetic energy has a maximum growth factor of 0.84 , one order of magnitude less than in experiments 1 and 2 . On the other hand, the growth of the potential energy is only $20 \%$ less than in experiment 1 since the perturbation extracts potential energy from the mean thermal front and also propagates from a stable to less stable region.

In experiment $3 \mathrm{~b}$ we set the geostrophic wind to $u_{g}=$ $-3 \mathrm{~m} \mathrm{~s}^{-1}, v_{g}=0$. The steady secondary circulation for this experiment, shown in Fig. 12, is substantially different from the previous cases of experiments 1-3 (Fig. 1). The opposite flow in the wind component normal to the thermal front, $\bar{u}$, results in the advection of the perturbation by the mean circulation from the warm and less stable part of the front toward the cooler and more stable part. This has a large effect on the maximum growth of the total energy factor, which is only 2.9 at $\tau=1.4 \mathrm{~h}$, that is, two orders of magnitude smaller than in the previous runs. Also, the difference in the wind component parallel to the front, $\bar{v}$, between this experiment and experiments $1-2$ results in a much weaker kinetic energy growth factor of 0.3 .

\section{f. Kinetic versus potential energy growth explored using the norm kernel}

In the above experiments we found that only a small fraction of the available potential energy of the growing anomaly is converted to kinetic energy. This is most prominent in the case in which $u_{g}=v_{g}=0$ since the maximum growth in the kinetic energy is less than 1 , while in the potential energy it is 213. In this section we examine the sensitivity to different norm kernels in order to obtain insight into this issue. Consider a norm kernel that is of a modified energy form,

$$
Y=u^{\prime 2}+v^{\prime 2}+\gamma \alpha \theta^{\prime 2}
$$

where $\gamma$ is a prescribed weight of the potential energy relative to kinetic energy: $\gamma=1$ corresponds to the true total energy.

We investigate two extreme experiments: experiment 4 with $\gamma=10^{-3}$ and experiment 5 with $\gamma=10^{3}$. In experiment 4 the optimal initial perturbation is constrained to have only potential energy for any value of $\tau$, and we find that the structure of $\theta^{\prime}$ is similar to the initial perturbation in experiment 3 (the case where $\gamma=1$ ). The maximum growth of the total and potential energy is obtained for $\tau=2.8 \mathrm{~h}$ and the growth factor reaches 98 . The kinetic energy growth factor reaches its maximum value of 0.3 for $\tau=7.7 \mathrm{~h}$. The structure of the mature perturbation is similar to the mature perturbation in experiment 3.

In experiment 5 the optimal initial perturbation is constrained to have only kinetic energy and the structure of $u^{\prime}, v^{\prime}$, and $w^{\prime}$ is found to be similar to the initial perturbation in experiment 3. The maximum growth factor of the total and potential energies is 122 , obtained at $\tau=2.8 \mathrm{~h}$. The kinetic energy reaches its maximum growth of 1.13 at $\tau=0.7 \mathrm{~h}$. In the initial perturbation $u^{\prime}$ is located within the inversion just above the AMBL, so the initial perturbation is later advected into the AMBL. The structure of the mature perturbation is similar to the mature perturbation of experiment 3 .

From these two cases we can conclude that the potential energy always has the largest and fastest growth. We can identify two reasons for this observation. First, the mean APE is larger by two orders of magnitude than the mean kinetic energy of the steady background flow. Second, we showed above that during the first stage of growth there is a significant transfer of kinetic to potential energy, which seems to prevent the development of a meaningful kinetic energy growth in spite of the significant mean shears that could be used to extract perturbation kinetic energy. 
(a) time $=0.0$

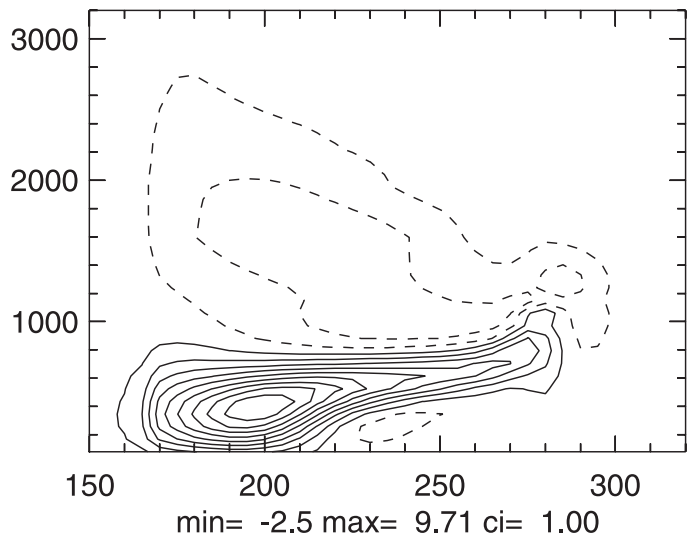

(c) time $=0.0$

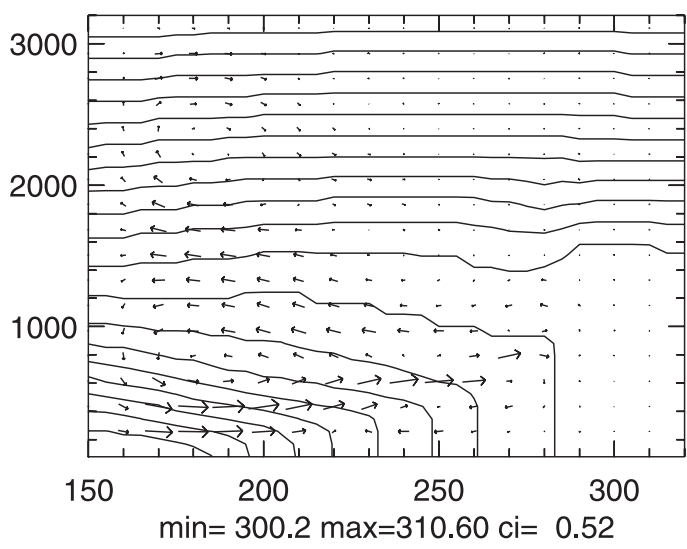

\section{Conclusions}

Strong SST fronts are found in many parts of the World Ocean including, for example, the Gulf Stream front and the Kuroshio front in the Pacific Ocean. These SST fronts induce a significant atmospheric "secondary circulation" across the front. In this paper we examined the generalized stability of such steady secondary circulations to small perturbations. The secondary circulations examined are steady solutions to a nonlinear numerical model of the dynamics in a vertical cross section perpendicular to the SST front that is assumed to be homogeneous in the along-front direction. These solutions are stable to small perturbations, so the growth of the energy of small perturbations is due to nonnormal dynamics.

In the basic experiment (experiment 1) the maximum total energy growth factor and potential energy growth factor are both $\sim 250$ and are obtained for an optimization time of $\tau=4.3 \mathrm{~h}$. The growth in the perturbation potential energy is due to extraction of potential energy from the steady thermal front in the boundary layer by (b) time $=0.0$

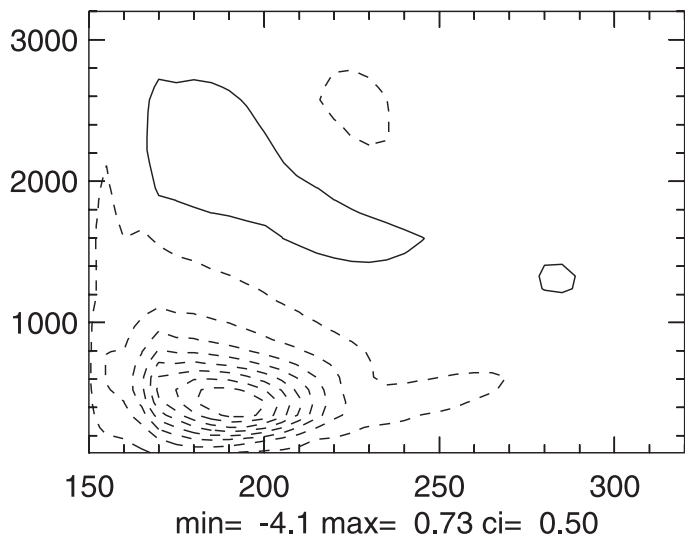

FIG. 10. Optimal initial perturbation in experiment 3 using an optimization time of $\tau=2.8 \mathrm{~h}$ (showing only the part of the domain over the front), panels and contour levels as in Fig. 4: $\max \left(u^{\prime}\right)=6 \mathrm{~cm} \mathrm{~s}^{-1} ; \max \left(w^{\prime}\right)=$ $0.15 \mathrm{~cm} \mathrm{~s}^{-1}$ what we term a "horizontal buoyancy flux", which corresponds to $\left\langle\alpha u^{\prime} \theta^{\prime} \bar{\theta}_{x}\right\rangle^{*}$. The finding that this term plays an important role in the nonnormal growth is an important novel finding of this work since horizontal variations in the mean state have not been considered in nonnormal growth analysis previously. Another source of growth of the available potential energy is the movement of the perturbation from a region with stable stratification to a region where the stratification is less stable. Kinetic energy extraction is also maximal in the front area due to the large mean shear there. As the perturbation travels out of the frontal region, the role of these source terms becomes small and the growth of the potential energy stops. We found the results to be especially sensitive to the prescribed synoptic geostrophic wind at the model's top boundary and examined this sensitivity in detail.

In all experiments done in this paper the available potential energy (APE) of the perturbation is two orders of magnitude larger than its kinetic energy. We identified two reasons for this observation. First, the mean APE is larger by two orders of magnitude than the mean 
(a) time $=2.8$

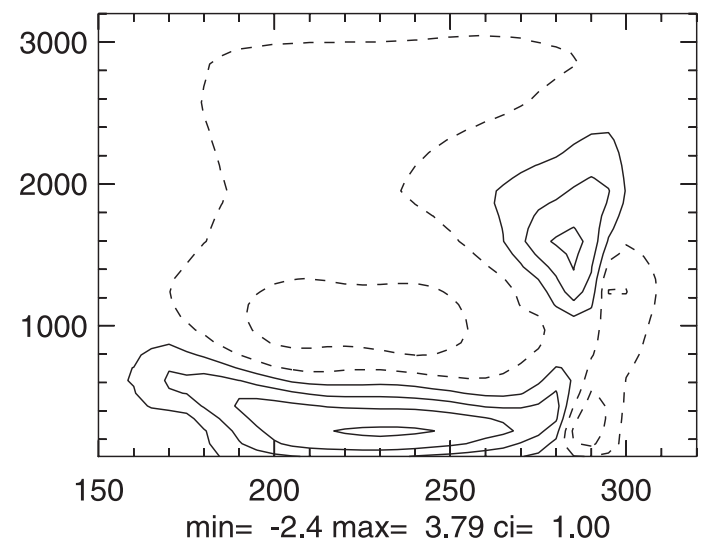

(c) time $=2.8$

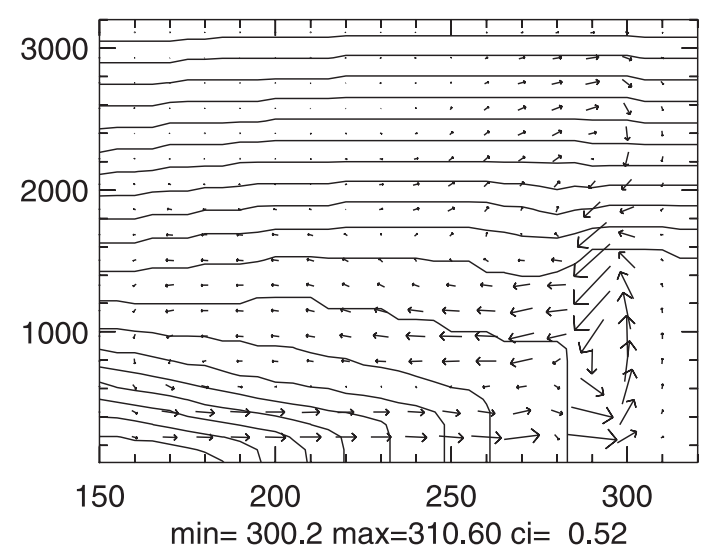

kinetic energy of the steady background flow. Second, there is significant transfer of kinetic to potential energy in the initial stages of the growth.

The steady state of our nonlinear model is stable with no intrinsic variability, consistent with the linear propagator being stable to small perturbations. Transient eddies are therefore expected only if initial perturbations are explicitly added to the system. Such perturbations

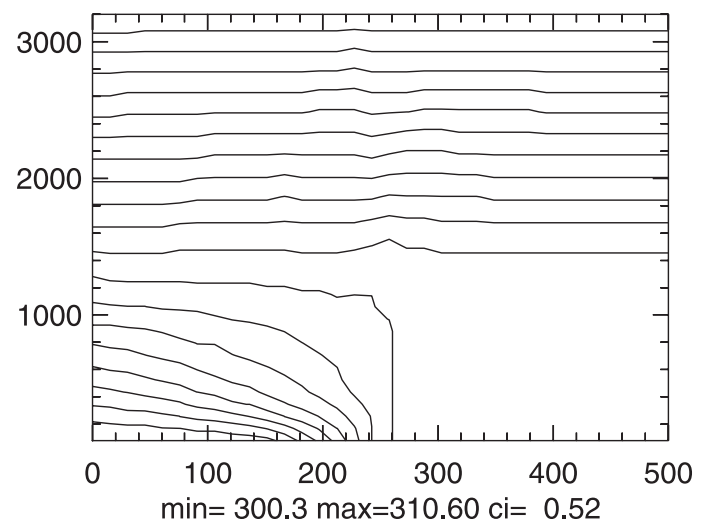

(b) time $=2.8$

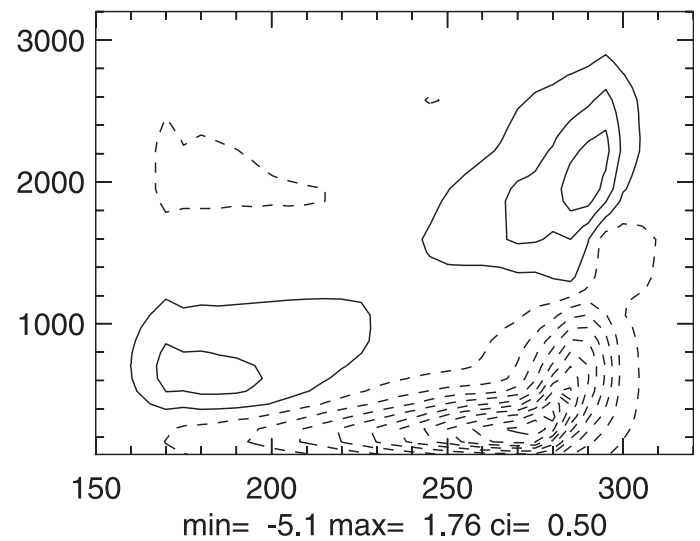

FIG. 11. Perturbation of expt 3 at $t=2.8 \mathrm{~h}$ (showing only part of the domain over the front), panels and contour levels as in Fig. 4: $\max \left(u^{\prime}\right)=9 \mathrm{~cm} \mathrm{~s}^{-1} ; \max \left(w^{\prime}\right)=$ $0.37 \mathrm{~cm} \mathrm{~s}^{-1}$. may only grow due yo nonnormal effects, as analyzed above. It would be of interest to compare the intrinsic variability of a low-viscosity nonlinear model with the nonnormal growth found here, but this is beyond the scope of the present study.

We emphasized several observable consequences of this study. Our results suggest that the growing perturbations lead to a momentum transport from altitudes

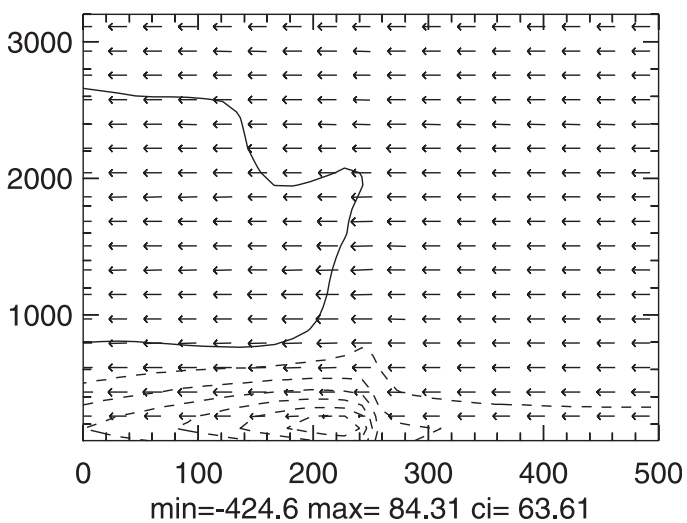

FIG. 12. As in Fig. 9 but for expt 3b with $u_{g}=-3 \mathrm{~m} \mathrm{~s}^{-1}, v_{g}=0: \min (\bar{u})=-3.9 \mathrm{~m} \mathrm{~s}^{-1} ; \max (\bar{w})=3 \mathrm{~cm} \mathrm{~s}^{-1}$. 
where the mean wind of the secondary circulation is strong (above $300 \mathrm{~m}$ ) down to the surface and can contribute to the increasing of the mean surface wind, as seen in the observations (Sweet et al. 1981; Chelton et al. 2006; Weissman et al. 1980). This mechanism may supplement the two mechanisms for the enhanced mean wind over the warm part of the front, which were already proposed in the literature and summarized in the introduction. Note that our mechanism would be effective even if the synoptic wind is weak, in which case the previously proposed transfer of momentum from the synoptic wind to the surface is expected to be less efficient. The cells resulting from the nonnormal growth would also enhance downward mixing of drier air from aloft, thereby drying the surface air over the warm part of the front. Indeed, the relative humidity near the surface decreases over the warm water, as shown for example over the Gulf Stream (Sweet et al. 1981, their Fig. 13b). Finally, the mature perturbations, found in our calculations, are characterized by large cells with ascending air. This upward flow advects humid air from the sea surface to heights of several kilometers, well above the boundary layer, where it can condense to form low-level clouds. This result is consistent with the observed low-level clouds over the warm side of the Gulf Stream and Agulhas Return Current (Small et al. 2008; Sublette and Young 1996; Minobe et al. 2008).

Acknowledgments. ET thanks the Weizmann Institute for its hospitality during parts of this work. ET and YF were supported by the NSF Climate Dynamics Program, Grant ATM-0754332. BF was supported by NSF ATM0736022 .

\section{APPENDIX}

\section{The Numerical Model}

The numerical algorithm of the model used here is described in Feliks (2004). The equations are applied to a staggered grid contained within a vertical plane extending in the $x$ coordinate perpendicular to the SST front. The horizontal grid interval was taken as $d x=$ $5 \mathrm{~km}$ and 106 grid points were utilized, covering a domain size of $525 \mathrm{~km}$ and 33 vertical levels at heights of 0 , $2.5,5,10,20,40,80,160,240,320,400,480,560,640,720$, $800,880,960,1040,1120,1280,1600,1920,2240,2560$, 2880, 3200, 3520, 3840, 4160, 4480, 4800, 5120, and $5440 \mathrm{~m}$.

A forward time scheme is used to approximate the time derivative. The "component by component splitting method" is used to solve the prognostic equations (Marchuk 1975). Horizontal advection terms are approximated by centered differencing, and the diffusion is solved explicitly. Vertical diffusion and advection are solved implicitly to allow large time steps. Sponge layers are used in the five grid points adjacent to the horizontal boundaries. Within the sponge layers, the vertical diffusion coefficient is larger by an order of magnitude. The time interval $d t=40 \mathrm{~s}$. The physical parameters are $K_{h}=$ $5 \times 10^{7} \mathrm{~cm}^{2} \mathrm{~s}^{-1}, K_{v}=10^{4} \mathrm{~cm}^{2} \mathrm{~s}^{-1}, f=14.585 \times 10^{-5}$ $\sin 32^{\circ}, \theta_{m}=300 \mathrm{~K}$, and $g=981 \mathrm{~cm} \mathrm{~s}^{-2}$.

The linearized model about the steady secondary circulation was integrated in a partial domain with 70 grid points in the horizontal and 23 vertical levels at heights $0,80,160,240,320,400,480,560,640,720,800,880,960$, $1040,1120,1280,1600,1920,2240,2560,2880$, and $3200 \mathrm{~m}$. The time step in the linearized model is $d t=$ $10 \mathrm{~s}$ : all other numerical and physical parameters were the same as in the fully nonlinear model.

\section{REFERENCES}

Buizza, R., 1995: Optimal perturbation time evolution and sensitivity of ensemble prediction to perturbation amplitude. Quart. J. Roy. Meteor. Soc., 121, 1705-1738.

_ , and T. N. Palmer, 1995: The singular-vector structure of the atmospheric global circulation. J. Atmos. Sci., 52, 1434-1456.

Chelton, D. B., M. H. Freilich, J. M. Sienkiewicz, and J. M. Von Ahn, 2006: On the use of QuikSCAT scatterometer measurements of surface winds for marine weather prediction. Mon. Wea. Rev., 134, 2055-2071.

Doyle, J., and T. Warner, 1990: Mesoscale coastal processes during GALE IOP 2. Mon. Wea. Rev., 118, 283-308.

Farrell, B. F., 1988: Optimal excitation of neutral Rossby waves. J. Atmos. Sci., 45, 163-172.

- 1989: Optimal excitation of baroclinic waves. J. Atmos. Sci., 46, 1193-1206.

— Autonomous operators. J. Atmos. Sci., 53, 2025-2040.

Feliks, Y., 2004: Nonlinear dynamics and chaos in the sea and land breeze. J. Atmos. Sci., 61, 2169-2187.

— M. M. Ghil, and E. Simonnet, 2004: Low-frequency variability in the midlatitude atmosphere induced by an oceanic thermal front. J. Atmos. Sci., 61, 961-981.

,-- , and,- 2007 : Low-frequency variability in the midlatitude baroclinic atmosphere induced by an oceanic thermal front. J. Atmos. Sci., 64, 97-116.

Giordani, H., and S. Planton, 2000: Modeling and analysis of ageostrophic circulation over the Azores oceanic front during the SEMAPHORE experiment. Mon. Wea. Rev., 128, 22702287.

Hoskins, B., 1975: The geostrophic momentum approximation and the semi-geostrophic equations. J. Atmos. Sci., 32, 233-242. , and F. Bretherton, 1972: Atmospheric frontogenesis models: Mathematical formulation and solution. J. Atmos. Sci., 29, 11-37.

Hsu, S., 1984: Sea-breeze-like winds across the north wall of the Gulf Stream: An analytical model. J. Geophys. Res., 89, 20252028.

Huang, C.-Y., and S. Raman, 1988: A numerical modeling study of the marine boundary layer over the Gulf Stream during cold air advection. Bound.-Layer Meteor., 45, 251-290. 
Joly, A., 1995: The stability of steady fronts and the adjoint method: Nonmodal frontal waves. J. Atmos. Sci., 52, 3082-3108.

Lohmann, G., and J. Schneider, 1999: Dynamics and predictability of Stommel's box model. A phase-space perspective with implications for decadal climate variability. Tellus, 51A, 326-336.

Marchuk, G. I., 1975: Methods of Numerical Mathematics. Springer, $316 \mathrm{pp}$.

Minobe, S., A. Kuwano-Yoshida, N. Komori, S.-P. Xie, and R. J. Small, 2008: Influence of the Gulf Stream on the troposphere. Nature, 452, 206-209, doi:10.1038/nature06690.

Moore, A. M., 1999: Wind-induced variability of ocean gyres. Dyn. Atmos. Oceans, 29, 335-364.

— ocean-atmosphere model of ENSO. I. Thermodynamics, energetics and error growth. Quart. J. Roy. Meteor. Soc., 123, 953-981.

O'Neill, L., D. Chelton, and S. Esbensen, 2003: Observations of SST-induced perturbations of the wind stress field over the Southern Ocean on seasonal time scales. J. Climate, 16, 2340 2354.

- $-\longrightarrow,-$, and F. Wentz, 2005: High-resolution satellite measurements of the atmospheric boundary layer response to SST variations along the Agulhas Return Current. J. Climate, 18, 2706-2723.

Park, K., P. Cornillon, and D. Codiga, 2006: Modification of surface winds near ocean fronts: Effects of Gulf Stream rings on scatterometer (QuikSCAT, NSCAT) wind observations. J. Geophys. Res., 111, C03021, doi:10.1029/2005JC003016.

Penland, C., and P. D. Sardeshmukh, 1995: The optimal growth of tropical sea surface temperature anomalies. J. Climate, 8, 19992024.
Sikora, T., G. Young, R. Beal, and J. Edson, 1995: Use of spaceborne synthetic aperture radar imagery of the sea surface in detecting the presence and structure of the convective marine atmospheric boundary layer. Mon. Wea. Rev., 123, 36233632.

Small, R. J., and Coauthors, 2008: Air-sea interaction over ocean fronts and eddies. Dyn. Atmos. Oceans, 45, 274-319, doi:10.1016/ j.dynatmoce.2008.01.001.

Sublette, M., and G. Young, 1996: Warm-season effects of the Gulf Stream on mesoscale characteristics of the atmospheric boundary layer. Mon. Wea. Rev., 124, 653-667.

Sweet, W., R. Fett, J. Kerling, and P. LaViolette, 1981: Air-sea interaction effects in the lower troposphere across the north wall of the Gulf Stream. Mon. Wea. Rev., 109, 1042-1052.

Tokinaga, H., Y. Tanimoto, and S. Xie, 2005: SST-induced surface wind variations over the Brazil-Malvinas confluence: Satellite and in situ observations. J. Climate, 18, 3470-3482.

Tziperman, E., and P. J. Ioannou, 2002: Transient growth and optimal excitation of thermohaline variability. J. Phys. Oceanogr., 32, 3427-3435.

Wai, M., and S. Stage, 1989: Dynamical analyses of marine atmospheric boundary layer structure near the Gulf Stream oceanic front. Quart. J. Roy. Meteor. Soc., 115, 29-44.

Warner, T., M. Lakhtakia, J. Doyle, and R. Pearson, 1990: Marine atmospheric boundary layer circulations forced by Gulf Stream sea surface temperature gradients. Mon. Wea. Rev., 118, 309-323.

Weissman, D., T. Thompson, and R. Legeckis, 1980: Modulation of sea surface radar cross section by surface stress: Wind speed and temperature effects across the Gulf Stream. J. Geophys. Res., 85, 5032-5042. 